Građevinski materijali i konstrukcije

Building Materials and Structures

journal homepage: www.dimk.rs

doi: 10.5937/GRMK210395D UDK: 624:005.915

Technical paper

\title{
Allocation and selection of equipment for concrete works using fuzzy linear ${ }^{\star}$ programming
}

\author{
Abel Duran ${ }^{* 1)}$, Nataša Praščević ${ }^{1)}$ \\ 1) Faculty of Civil Engineering Univeristy of Belgrade, King Alexander Boulevard 73, 11000 Belgrade, Serbia
}

\section{Article history}

Received: 19 July 2021

Received in revised form: /

Accepted: 20 August 2021

Available online: 30 September 2021

\section{Keywords}

fuzzy linear programming,

construction equipment,

concrete works

\begin{abstract}
The aim of this research is focused on the problem of allocation and selection of the construction equipment when construction firms bid for construction projects. The main objective of the selection of construction equipment is to ensure the timely completion of all considered projects, while at the same time the planned budget is fulfilled. In this paper fuzzy linear programming is applied with the fuzzy objective function and fuzzy constrains. The proposed mathematical model is applied for optimal selection and allocation of equipment for five projects with different quantities of concrete works and general budget.
\end{abstract}

\section{Introduction}

The optimal selection of construction equipment or complex construction mechanization for the execution of specific construction works is today simply unthinkable without the application of modern methods of analysis during the selection process. The application of fuzzy linear programming as a modern methodology of analysis allows us to, from several alternative solutions, choose the best ones that give optimal results for the appropriate constraints [1].

The problem that big construction companies increasingly encounter in practice is the selection and allocation of construction equipment in the event of the need to implement multiple construction projects simultaneously. Bearing in mind that the works are often performed on foreign markets, often on other continents, the company, when entering a specific market, needs to purchase appropriate construction equipment for specific works. The key reason for analysis of the optimal selection of equipment for concrete works comes from the large number of concrete structures built in the world every year (today, the production of concrete is about 9.4 billion tons per year [2]). The costs of concrete works during the construction of the facility can amount to up to $30 \%$ of the total construction costs. Also, during the realization of construction projects in parts of the world with extremely low or extremely high temperatures, these costs are often up to $20 \%$ higher than the costs for the same concrete works in Europe [3].

Considering all the data above explaining the concrete usage during the realization of construction projects, as well as share of concrete works in total costs, a quality solution for the procurement of equipment for concrete works is one of the basic prerequisites for submission of quality bid, winning the project during tender process and make a profit on the project.

In this paper, the process of selection and allocation of construction equipment will be presented on a realistic example from practice which implies a wider choice of equipment (selection of type and category of equipment according to the constructive ability of the machine to perform certain works [4]), determining the optimal number of machines for realization of several construction projects, where the company has a roughly defined budget for the realization of this task

A systematic solution to this problem is achieved by answering 5 key questions:

- What activities need to be performed on the realization of concrete works,

- What is the scope of work,

- How long it takes to do the work,

- What types and category of machines can perform defined activities (wider choice),

- What is the necessary capacity of the machines that need to be engaged.

As each construction project is emphatically unique [3], the intention of the author is to provide a universal and efficient solution to the problem of allocation of construction equipment for concrete works on several different projects simultaneously using the method of fuzzy linear programming.

\section{Problem definiton, analysis of project characteristics and defining the criteria function with constraints}

As mentioned earlier, construction companies often face the problem of allocating their resources when biding for

\footnotetext{
* Paper presented at ASES 2020 Symposium, Arandjelovac, Serbia, May 2021.

Corresponding author:

E-mail address: aduran@grf.bg.ac.rs
} 
multiple construction projects at the same time. For the purposes of this research, we will analyze the case of a representative contracting company that explores the financial aspects and justification of entering the foreign market will be analyzed.

\subsection{Problem definition}

The contractor has decided to bid for five large projects abroad. As the company has not execute construction works in the country where the projects are being built earlier, it is necessary to envisage the procurement of the necessary construction equipment. As the central concrete plant is rented and not owned by the company, the costs of procurement and operation of this plant will not figure in the analysis of work activities and defining the criteria function with constraints. In addition to the preparation of the concrete mixture in the concrete plant, it is necessary to perform external and internal transport of the concrete mixture and pouring of concrete [5]. The concrete plant is on average 10 $\mathrm{km}$ away from the construction site. At the stated distance, the only machine that can perform external transport (from the concrete factory to the construction site [4]) of the concrete mixture in a quality way is the concrete mixer truck [4]. As the quantities of concrete to be poured on each of the construction sites are quite large, it will be necessary to use a mobile concrete pump for the internal transport of the concrete mixture (from the concrete mixer truck to the place where concrete needs to be poured [4]). The consolidation of fresh concrete mixture is performed by concrete vibrators that induce vibrations from 100 to $250 \mathrm{~Hz}$ which expels entrapped air from freshly placed concrete and packs the aggregate particles together so as to increase the density of concrete [6].

Furthermore, an approximate budget of between 700 and 800 thousand euros is available to the company for the procurement of construction equipment and for performing concrete works.

\subsection{Analysis of project characteristics}

Regardless of the place, type and nature of the construction works, each construction project is defined by three important elements: scope of work (subject of the contract), deadline (time for which it is necessary to complete a certain work) and price [3] .

As this specific example considers the selection and allocation of construction equipment for concrete works, the following is a tabular presentation of the project, with the quantities of concrete works to be poured, as well as the deadline within which the aforementioned works should be performed.

In addition to the type of project, the scope of works and planned time for which the works should be performed, the required hourly production $U_{p \text {,req }}$ will be calculated and shown in the table for each of the projects. The required hourly production is the minimum performance that each construction machine in combination should achieve in order to complete planned scope of work within a defined period of time and is calculated as:

$U_{p, r e q}=Q / t\left[m^{3} / h\right]$

where is:

$Q\left[\mathrm{~m}^{3}\right]$ - quantity of work that needs to be done;

$t[h]$ - time for which the works need to be performed.

\subsection{Defining criteria function}

As the contractor for the procurement of construction equipment for concrete works has an approximate budget of between 700 and 800 thousand euros, it means that the criteria function is an approximate value, i.e., it can be considered as a "fuzzy number" [1].

Having in mind the above, the criteria function will be presented as the amount of available financial resources that will be used for the procurement of construction equipment for concrete works. The criteria function $(F)$ will be presented as the sum of the price of the machine and the number of different types of machines necessary to perform the work and meet the required hourly production on each of the projects:

$T=P_{1} N_{1}+P_{2} N_{2}+P_{3} N_{3}$

where is:

$T$ - criteria function,

$P_{i}$ - the market price of the specific construction machine,

$\mathrm{N}_{i}$ - number of specific construction machines that need to be procured.

Table 1. Information on projects and required hourly production

\begin{tabular}{|c|c|c|c|c|c|}
\hline Project ID & PRO1 & PRO2 & PRO3 & PRO4 & PRO5 \\
\hline Project type & hotel & building & bridge & hotel & building \\
\hline Quantity of works $Q\left[\mathrm{~m}^{3}\right]$ & 10,500 & 8,400 & 13,500 & 11,200 & 9,000 \\
\hline Duration of works in days d [day] & 40 & 35 & 30 & 35 & 25 \\
\hline Shift duration s [h] & 10 & 8 & 8 & 12 & 8 \\
\hline Number of shifts $n[-]$ & 1 & 1 & 2 & 1 & 2 \\
\hline Duration of works in hours $t=d^{*} s^{*} n[h]$ & 400 & 280 & 480 & 420 & 400 \\
\hline Required hourly production $U_{p, r e q}\left[\mathrm{~m}^{3} / \mathrm{h}\right]$ & 26.25 & 30.00 & 28.13 & 26.67 & 22.50 \\
\hline
\end{tabular}


2.4 Characteristics of available construction machines on the market

Having in mind the ratio of machine dimensions and construction site dimensions, necessary space for maneuver, as well as available manufacturers on the market, the company made a strategic decision to procure machines of the same type and the same manufacturer for each category of machine according to the table below:

\section{Definition of the mathematical model}

As the financial resources available to the contractor for the procurement of construction equipment are given as an approximate amount between 700 and 800 thousand euros, we can present it in the form of a fuzzy triangular number $T=\left(t_{l}, t_{m}, t_{r}\right)$. As the coefficients that have been estimated appear in the formulas for the calculation of machines hourly production, therefore the hourly production can be presented

Table 2. Information on specific machines and their hourly production

\begin{tabular}{|c|c|c|c|c|}
\hline ID & Machine type & Manufacturer and label & $\begin{array}{c}\text { Market value } \\
{[\boldsymbol{\epsilon}]}\end{array}$ & $\begin{array}{c}\text { Hourly production } \\
{\left[\mathbf{m}^{\mathbf{3} / \boldsymbol{h}]}\right.}\end{array}$ \\
\hline CP & concrete pump & Putzmeister BSF 36.16H & 180,000 & 68.00 \\
\hline CM & concrete mixer truck & Mercedes Actross 4841 & 123,000 & 7.41 \\
\hline CV & concrete vibrator & Vibrofix IHE 66 & 1,500 & 13.28 \\
\hline
\end{tabular}

\subsection{Constraints definition}

It is necessary to define the appropriate constraint definition for each project respectively. The specific constraint is set on the basis of the rule that the hourly production for each machine type (number of machines multiplied by the corresponding hourly production of the machine) is greater than or equal to the required hourly production for each project [4].

PRO1: $U_{p}^{C P} N_{1} \geq U_{p, r e q}{ }^{P R O I} ; U_{p}^{C M} N_{2} \geq U_{p, r e q}^{P R O I}$; $U_{p}{ }^{C V} N_{3} \geq U_{p, r e q}{ }^{P R O I}$

PRO2: $U_{p}{ }^{C P} N_{1} \geq U_{p, r e q}{ }^{P R O 2} ; U_{p}{ }^{C M} N_{2} \geq U_{p, r e q}{ }^{P R O 2}$;

$U_{p}{ }^{C V} N_{3} \geq U_{p, r e q}{ }^{P R O 2}$

PRO3: $U_{p}^{C P} N_{1} \geq U_{p, r e q}{ }^{P R O 3} ; U_{p}^{C M} N_{2} \geq U_{p, \text { req }}{ }^{\text {PRO3 }}$;

$U_{p}{ }^{C V} N_{3} \geq U_{p, r e q} P R O 3$

PRO4: $U_{p}^{C P} N_{1} \geq U_{p, r e q}{ }^{\text {PRO4 }} ; U_{p}{ }^{C M} N_{2} \geq U_{p, r e q}{ }^{\text {PRO4 }}$;

$U_{p}{ }^{C V} N_{3} \geq U_{p, r e q}{ }^{P R O 4}$

PRO5: $U_{p}^{C P} N_{I} \geq U_{p, r e q}{ }^{P R O 5} ; U_{p}{ }^{C M} N_{2} \geq U_{p, r e q}{ }^{P R O 5}$;

where is:

$P R O_{i}$ - project ID,

$U_{P} X X_{-} \quad$ specific machine hourly production,

$U_{p, p o t}{ }^{P R O i}$ - required hourly production for specific project,

$\mathrm{N}_{i}-\quad$ number of specific construction machines that need to be procured. also in the form of a fuzzy triangular numbers $U_{p}^{x x}=(u)^{x x}$, $\left.u_{m}{ }^{x x}, u^{x x}\right)[1]$.

The financial resources and hourly production of the machines presented in the form of a fuzzy triangular number are shown in Table 3:

As the financial resources and practical effects for the concrete pump, concrete mixer truck and concrete vibrator are presented in the form of fuzzy triangular numbers, after re-arranging of mathematical equations following mathematical model is defined [1]:

$$
\begin{aligned}
& \max F=h \\
& P_{I} N_{l}+P_{2} N_{2}+P_{3} N_{3} \geq t_{l}+h\left(t_{l}-t_{r}\right) \\
& P_{I} N_{l}+P_{2} N_{2}+P_{3} N_{3} \leq t_{r}+h\left(t_{r}-t_{l}\right) \\
& U_{p}^{C P} N_{l} \geq \max _{C P}\left(U_{p, r e q}{ }^{P R O i}\right) \\
& U_{p}{ }^{C M} N_{2} \geq \max _{C M}\left(U_{p, \text { req }}{ }^{\text {PROi }}\right) \\
& U_{p}{ }^{C V} N_{3} \geq \max _{C V}\left(U_{p, r e q}{ }^{P R O i}\right)
\end{aligned}
$$

\begin{tabular}{|c|c|c|c|c|}
\hline fuzzy label & Total Budget $T[€]$ & $U_{p}^{C P}\left[m^{3} / h\right]$ & $U_{p}^{C M}\left[m^{3} / h\right]$ & $U_{p}^{c v}\left[m^{3} / h\right]$ \\
\hline LEFT [80\%] $\left(t_{t} ; u_{l}\right)$ & 700,000 & 54.50 & 5.93 & 10.62 \\
\hline MIDDLE [100\%] $\left(t_{m} ; u_{m}\right)$ & - & 68.00 & 7.41 & 13.28 \\
\hline RIGHT [110\%] $\left(t_{r} ; u_{r}\right)$ & 800,000 & 74.80 & 8.15 & 14.61 \\
\hline fulfilment level [ki] & - & 0.8 & 0.8 & 0.8 \\
\hline
\end{tabular}

The equations shown from (9) to (13) can be represented in a generally derived fuzzified form as follows:

$$
u_{m}{ }^{X X} N_{i}+\left(1-k_{i}\right)\left(u_{r}{ }^{X X} N_{i}-u l^{X X} N_{i}\right) \geq \max _{X X}\left(U_{p, r e q}{ }^{P R O i}\right)
$$

Table 3. The total budget and hourly production in the form of a fuzzy triangular number 


\section{Results and discussion}

The initial step for solving the aforementioned equations is that the degree of satisfaction $k_{i}$ (which is directly related to the hourly production of construction equipment for concrete works) is previously set, and that the degree of satisfaction of the requirements $h$ is maximized.

When the corresponding numerical data previously obtained in points 2.2., 2.4 and Table 3 of this paper are inserted into equations (8) to (13), i.e. equations (8) to (10) and equation in the generally derived fuzzified form (14), we obtain the following system of equations:

$$
\begin{aligned}
& \max F=h \\
& 180,000 N_{l}+123,000 N_{2}+1,500 N_{3}-100,000 h \geq \\
& \geq 700,000 \\
& 180,000 N_{1}+123,000 N_{2}+1,500 N_{3}-100,000 h \leq \\
& \leq 800,000 \\
& N_{l} \geq 0,32 \\
& N_{2} \geq 3,82 \\
& N_{3} \geq 2,13
\end{aligned}
$$

It is recommended to solve this problem with the help of modern software solutions, and in this paper the problem is defined in the software package "Matlab" by defining the parameters of the itlinprog function [7]. The following solutions were obtained:

$N_{1}=1$

$N_{2}=5$

$N_{3}=3$

$\max F=h=0.99$

$T=799,500 €$

where is:

$N_{l}$ - number of concrete pumps

$N_{2}$ - number of concrete mixer trucks

$N_{3}$ - number of concrete vibrators

$T$ - Financial resources necessary for the procurement of all construction equipment.

It can be noticed that the calculated amount of financial resources meets the pre-set constraints in terms of available financial resources, as well as that the number of necessary machines multiplied by their hourly production meets the required hourly production to meet all 5 considered projects.

The amount of available funds is presented in the form of a range between two acceptable values because in practice it is not considered appropriate to buy either too cheap or too expensive equipment and for such a situation the application of the considered target function as a fuzzy number proved to be justified. In case only the maximum value is set as a constraint condition, it would be necessary to observe the criteria function in a different way, because the fuzzy number method when it is not a range of acceptable values is not adequate

In case the projects did not take place abroad and new equipment did not need to be procured (equipment from the company's existing fleet would be used) the problem that the company should solve is the choice of the optimal combination of machines that can complete all necessary operations and meet the required hourly production for each of the projects. To solve this problem, one of the ways would be to apply the method of linear programming.

\section{Conclusion}

This paper analyzed a practical example from construction industry that contractors encounter very often when entering a new market and when they are bidding for the several similar construction projects at the same time. The example from this paper, which analyzes the procurement of necessary construction equipment for concrete works on 5 different construction projects, was solved by applying fuzzy linear programming with the fuzzy objective function and fuzzy constrains. As a solution to the problem, it was obtained that, at the degree of satisfaction of the requirements $h=0.99$, it is necessary to procure:

- 1 concrete pump (Putzmeister BSF $36.16 \mathrm{H}$ ) with a purchase value of $€ 180,000$

- 5 concrete mixer trucks (Mercedes Actross 4841) with a purchase value of $€ 123,000$

- 3 concrete vibrators (Vibrofix IHE 66) with a purchase value of $€ 5,000$

Regardless of the applied model and the specific problem that is being solved, when it comes to the analysis of construction equipment, it is necessary to perform a permanent fine-tuning of the mathematical model and input parameters. The authors recommend that the hourly production construction equipment, as well as their purchase values, be observed in real time and that the mathematical model be fine-tuned in a timely manner through input parameters and constraints.

The mathematical model presented in this paper on one practical problem can be considered sufficient and general, because a simple substitution of input parameters and constraints gives a model for any other similar case that the contractor may encounter in practice.

The model presented in this paper has limitations in its application if the projects under consideration are located close to each other, i.e. when it is possible to apply the same machine to several construction sites at the same time.

One of the directions for future researches is to compare the solution obtained by applying fuzzy linear programming with the solution obtained by another optimization method.

\section{Acknowledgment}

The preparation of this paper was supported through a scientific research project of the Ministry of Education, Science and Technological Development TP 36038 "Development of a method for the design and construction documentation of installation networks in buildings compatible with the BIM process and relevant standards."

\section{References}

[1] Tiodorović D., Kikuchi S.: Fuzzy sets and application in transport industry, Faculty of Transport and Traffic Engineering University of Belgrade, Belgrade, ISBN 8680897-42-6, 1994.

[2] Marinković S.: Design of concrete structures with regards to their impact on the environment, Conference proceedings, National Symposium of the Association of Structural Engineers of Serbia, Zlatibor, ISBN 978-86850073-04-05, 2008. 
[3] Ivković B., Popović Ž.: Construction project management, Građevinska knjiga, Belgrade, ISBN 86395-0447-4, 2005.

[4] Mirković S.: Construction equipment, Građevinska knjiga, Belgrade, ISBN 86-395-0434-2, 2005.

[5] Praščević Ž.: Organization of construction works, Zavod za udžbenike, Belgrade, ISBN 86-17-022-57-4, 1992.
[6] Arizanović D., Petronijević P., Beljaković D.; Technology of construction works, Faculty of Civil Engineering University of Belgrade, Belgrade, ISBN 978-86-7518-157-6, 2015.

[7] Klem N., Kovačević M., Praščević N., Nedeljković Đ.: Basis of programming in MATLAB, Građevinska knjiga, Belgrade, ISBN 978-86-395-0609-4, 2010. 
